\title{
Beşeri Sermaye ve Doğrudan Yabancı Yatırımlarının Ekonomik Büyüme ile İlişkisi: OECD Ülkeleri Üzerine Panel Veri Analizi
}

\author{
Şakir İSLEYEN ${ }^{1}$
}

$\ddot{O} z$

Beşeri sermayenin yüksek olduğu ülkelerde istikrarlı ve gelişmiş ekonominin olduğu literatürlerde yer almaktadır. Aynı zamanda güven ve istikrarın hâkim olduğu ülkelerde de doğrudan yabancı yatırımlar büyük bir önem taşımaktadır. Doğrudan yabancı yatırımlar ülkeye döviz girişini sağlamakla birlikte ülkede istihdam alanı yaratarak ekonomik kalkınmaya büyük katkı sağlamaktadır. Bu çalışmada 36 OECD ülkesine ait Beşeri Sermaye (BS) ve Doğrudan Yabancı Yatırımlarının (DYY) Ekonomik Büyüme(GSYİH) ile ilişki panel eşbütünleşme testi ile analiz edilmiştir. Sonuç olarak BS ve DYY ile GSYİH arasında eşbütünleşme olduğu görülmüştür. Ayrıca uzun dönemli eşbütünleşme testi sonucunda da BS ve DYY ile GSYİH arasında pozitif yönlü bir ilişkinin olduğu gözlemlenmiştir.

Anabtar Kelimeler: Ekonomik büyüme, Panel veri analizi, Eşbütünleşme, Enerji tüketimi

\section{The Relationship between Human Capital and Direct Foreign Investments and Economic Growth: Panel Data Analysis on OECD Countries}

\section{Abstract}

It is included in the literature that there is a stable and developed economy in countries with high human capital. At the same time, foreign direct investments are of great importance in countries where trust and stability are dominant. While foreign direct investments provide foreign currency inflow to the country, it creates a field of employment in the country and contributes greatly to economic development. In this study, the relationship between Human Capital (BS) and Foreign Direct Investments (FDI) of 36 OECD countries with Economic Growth (GDP) was analyzed by panel cointegration test. As a result, it was observed that there is cointegration between BS and FDI and GDP. In addition, as a result of the long-term cointegration test, it was observed that there was a positive relationship between BS and FDI and GDP.

Key Words: Economic growth, Panel data analysis, Cointegration, Energy consumption

\section{Atıf İçin / Please Cite As:}

İşleyen, Ş. (2020). Beşeri sermaye ve doğrudan yabancı yatırımlarının ekonomik büyüme ile ilişkisi: OECD ülkeleri üzerine panel veri analizi. Manas Sosyal Araşttrmalar Dergisi, 9(3), 1554-1563.

Geliş Tarihi / Received Date: 04.05.2020

Kabul Tarihi / Accepted Date: 31.05.2020

\footnotetext{
${ }^{1}$ Dr. Öğr. Üyesi - Van Yüzüncü Yıl Üniversitesi, İktisadi ve İdari Bilimler Fakültesi, Ekonometri Bölümü, sakirisleyen@yyu.edu.tr - ORCID: 0000-0002-8186-1990
} 


\section{İŞLEYEN}

Beşeri Sermaye ve Doğrudan Yabancı Yatırımlarının Ekonomik Büyüme ile İlişkisi: OECD Ülkeleri Üzerine Panel Veri Analizi

\section{Giriş}

Beşerî sermayenin ekonomik büyüme ile olan ilişkisi, modern büyüme literatürünün önemli tartışma konularından birisi olmuştur. Gelir yaratan ekonomik faaliyetlere katkıda bulunan beşerlerdeki bilgi, beceri ve benzer nitelikler olarak tanımlanan beşerî sermaye, kişiye yapılan yatırımlarla birlikte artış göstermekte ve üretim sürecinin çok önemli bir girdi olarak yerini almaktadır. Bu sebeple, beşerî sermaye ve ekonomik büyüme arasında olan ilişki, büyümenin kaynaklarını inceleyen araştırmacıların yanı sıra kalkınma politikalarını oluşturan kurum ve kurullarında ilgi alanlarından birini oluşturmaktadır. İktisat bilimi doğduğundan bu yana beşerî sermaye kavramı kullanılmıştır fakat insan faktörünün üretimin farklı bir sermaye unsuru olduğuna dair görüşler çoğunlukla II. Dünya Savaşı'ndan sonra teorik olarak incelenmeye başlanmıştır (Kıker, 1971, s. 51-53).

Ekonomik büyümenin teorik modellerinde Nelson ve Phelps (1966); Lucas (1988); Becker, Murphy ve Tamura (1990); Rebelo (1992); ve Mulligan ve Sala-i Martin gibi iktisatçlar tarafindan eğitimin üzerinden beşerî sermayenin önemine değinilmiştir. Bunun yanı sıra ülke grupları arasında beşerî sermaye ve ekonomik büyüme ilişkisi üzerine, Romer (1990), Barro (1991), Kyriacou (1991), ve Benhabiband Spiegel (1992) tarafindan bir çok ampirik analiz yapılmıştır. Fakat birçok ülkenin veri kısıtı olduğu için (sınırlı eğitimsel veriler) yapılan çalışmalar sonucunda beklenen sonuçlar elde edilememiştir (Barro, 1992, s. 199). Barro ve Lee (1992, s. 199-213), 129 ülkenin 1960-1985 dönemleri arasında 5'er ylllk verilerini kullanarak bir ampirik çalıșma yapmıșlardır. Bu çalışmada ülkelerin ilkokul, ortaokul ve lise kademelerindeki okullaşma oranları incelenmiştir. Yapılan çalışmada, beşerî sermayenin fiziki sermaye üzerine yapılan yatırımlara ve verimliliğe etkisinin pozitif yönde olduğu, yatırımların ve verimliliğin ekonomik büyüme üzerine etkisinin de yine pozitif yönde olduğu sonucu elde edilmiştir. Dolayısıyla beşerî sermaye birikimin ekonomik büyüme üzerine olumlu etkisi olduğu sonucuna varılmıştır.

Türkiye üzerine yapılan çalışmalara baktığımız zaman, Kar ve Ağır'ın (1998, s. 51-68) 1926-1994 yılları arasında eğitim harcamalarının ve sağlık harcamalarının GSYH'ye oranı ve GSYH verileri kullanılarak beşerî sermaye ve ekonomik büyüme arasındaki ilişkinin analiz çalışmasıdır. Sağılı harcamaları ile reel gelir arasındaki ilişkiye bakıldığında nedenselliğin yönünün ekonomik büyümeden sağlık harcamalarına doğru olduğu, eğitim ile gelir ilişkisinde ise nedenselliğin yönünün eğitim harcamalarından büyümeye doğru olduğu görülmüştür. Sonuç olarak beşerî sermayenin ekonomik büyüme üzerinde uzun dönemli pozitif bir etkiye sahip olduğu gözlemlemişlerdir.

Doğrudan yabancı yatırımlar, yabancı ülkelere direkt yatırımın yapılması, var olan yabancı bir şirket ile ortaklaşa hareket edilmesi veya ortak girişim ile yeni bir şirketin kurulması şeklinde yapılmaktadır. OECD (Ekonomik İşbirliği ve Kalkınma Teşkilatı) ye göre doğrudan yatııımın eşiği yabancı bir şirkette asgari, \% 10 'luk hissedardır. Aynı zamanda OECD kuralları esnekliğe sahiptir. Doğrudan yabanc1 yatırım, yatay, dikey ve konglomera olmak üzere kategorize ediliyor. Yatay doğrudan yatırım, bulunduğu ülkede çalışma alanıyla aynı iş alanına sahip yabancı şirkete yapılan yatırım anlamındadır. Dikey doğrudan yatırım, yatırımcıların ana faaliyetlerinden farklı olmakla birlikte yine de temel iş alanıyla ilintili yatırım demektir.

Örnek (2008), 1996: 4-2006: 1 dönemi için VAR tekniği kullanarak yaptı̆̆1 çalışmada, kısa vadeli sermaye yatırımlarının ve doğrudan yabancı sermaye yatırımlarının ekonomik büyüme üzerinde pozitif etki oluşturduğu saptamıştır ve doğrudan yabancı sermaye yatırımlarının yurtiçi tasarruflar açısından olumlu etki oluşturduğunu ve kısa vadeli sermaye yatırımlarının yurtiçi tasarruflar açısından negatif etkiye sebep olduğunu aynı analizde belirtmiştir.

Nair-Reichert ve Weinhold (2001) 24 gelişmekte olan ülke için 25 yılllk bir dönemi incelemişlerdir. Çalısmada yabancı sermaye hareketlerinin ekonomik etkilerinin heterojen olduğunu tespit etmişlerdir. Çalışma sonucuna göre yabancı sermaye yatırımlarından ekonomik büyümeye doğru bir nedensellik olduğu belirlenmiştir. Choe (2003), sermaye hareketleri ve büyüme arasındaki ilişkiyi, 80 ülke için 1971-1995 dönemi için incelemiştir. Araştırmada VAR modeli kullanılmıştır. Çalışma sonucuna göre büyüme ve yabancı sermaye hareketleri arasında çift yönlü bir ilişki saptanmıştır.

Okuyan ve Erbaykal (2008) 9 gelişmekte olan ülke için 1970-2006 arası dönem için yaptıkları TodaYamamoto nedensellik analizinde, 9 ülkenin hepsinde yabancı yatırımlar ve ekonomik büyüme arasında bir ilişki bulunduğunu saptamışlardır.

Vergil ve Karaca (2010) 1980-2015 arası dönemde farklı ülkeler için yaptıkları panel veri analizinde, doğrudan yabancı sermaye yatırımları ve portföy yatırımlarının, ekonomik büyüme üzerinde pozitif bir etki 
oluşturduğunu, kısa vadeli sermaye yatırımlarının ekonomik büyüme üzerinde negatif bir etkiye sebep olduğunu saptamışlardır.

Bulut ve Aykırı (2018) 1998-2017 yılları arasında Türkiye ekonomisi için yaptıkları incelemede, kısa vadeli sermaye olarak bilinen sıcak para hareketleriyle ekonomik büyüme arasında uzun vadede eşbütünleşik ilişki olduğunu saptamışlardır. Bununla birlikte vektör hata düzeltme modeli yardımıyla elde edilen bulgulara göre kısa vadeli sermaye hareketleri ve büyüme arasındaki ilişkinin uzun vadede geçici bir istikrar sağladığını gözlemlemişlerdir.

\section{Materyal ve Yöntem}

Araştırma materyalı olarak 36 OECD ülkelerine ait GSYIH, BS ve DYY verileri 1999-2018 yıllarını kapsamaktadır. Veriler Dünya Bankası resmi web adresinden yıllık oranlar şeklinde temin edildikten sonra STATA 15 programına aktarılıp gerekli analizler yapılmıştır. Çalışmada Panel Veri Analiz Yöntemi ile değişkenler arasında Westerlund (2007) Panel Eşbütünleşme Testi uygulanmıştır. Eşbütünleşme testinden önce verilere uygulanacak birim kök test, kuşağını belirlemek adına Yatay Kesit Bağımlılık testi uygulanmış daha sonra yapılan analizler aşağıda başlıklar halinde detaylı şekilde ele alınmıştır.

\section{Yatay Kesit Bağımlılı̆̆}

Panel veri analizinde model tahminlemesi öncesinde ilk olarak panel yatay kesit bağımlılı̆̆1 test edilmelidir. Kalıntılar arasında korelasyonun sıfır olduğu varsayılmaktadır. Bu test ile birimler arası korelasyonun anlamlllığı istatistiki olarak araştırılmaktadır. Sabit etkili model de yatay kesit bağımlılı̆̆1 Lagrange Çarpanı ile test edilmektedir. $T>N$ olduğu durumda bu test kullanılmaya elverişlidir. Hem sabit hem tesadüfi etkili model için Pesaran tarafindan geliştirilmiş Pesaran CDLM testi kullanılmaktadır. $\mathrm{N}>\mathrm{T}$ olduğu durumda kullanılmaktadır. Diğer testler ise Friedman R ve Frees Q panel yatay kesit bağımlılı̆̆1 testleridir (Akay, 2018, s. 24). Çalışmada $N>T$ olduğu durumlarda kullanılan Pesaran CDLM testi kullanıldığı için aşğaıda bu test detaylı şekilde anlatılmışır.

\section{Pesaran $C D L M$ testi}

2004 yilında Pesaran tarafından önerilen testte ADF regresyonun tahmininden elde edilen kalıntılar kullanılmaktadır. Her bir birimin kendisi hariç tüm birimlerle korelasyonu hesaplanmaktadır. Bu nedenle $\mathrm{N} * \mathrm{~N}-1$ adet korelasyon hesaplanmaktadır. Bu test yapısal kırlma, heterojen ve durağan olmama durumlarında az sayıda örneklerde de performansı iyidir. CDLM test istatistiği aşağıdaki formülle hesaplanmaktadır (Yerdelen Tatoğlu, 2018, s. 106).

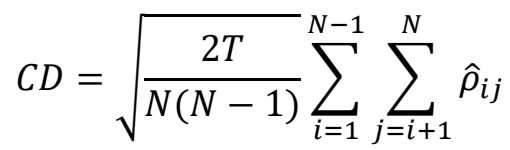

Pesaran $(2004,2006)$ tarafindan geliştirilen bu testte ise yatay kesiti hataları arasındaki korelasyon katsyıları toplamının sabit olduğu varsayımına dayanmaktadır. Sıfır hipotezi yatay kesit bağımlılı̆ı yoktur şeklindedir. Alternatif hipotez ise yatay kesit bağımllı̆̆ı vardır şeklindedir.

$H_{0}$ : Yatay kesit bağımlılı̆̆ yoktur.

$H_{1}$ : Yatay kesit bağımlılı̆̆ı vardır.

\section{Panel Birim Kök Testi}

Zaman serileri ile yapılan çalışmalarda analiz öncesinde o seriyi meydana getiren sürecin, zamanla sabit olup olmadığı başka bir deyişle, durağan bir seri olup olmadığına bakılmalıdır. Durağan olmayan seriler ile ekonometrik analizler yapilması sahte regresyona sebep olmaktadır. Sahte regresyon F, t testinin ve R2 değerleri sapmalı sonuçlar verebilmektedir (Yerdelen Tatoğlu, 2013, s. 198). Serilerin durağan olmaması sorunun zaman serileriyle çalış1lırken sıklıkla karşılaşılan bir durumdur. Sahte regresyon sorununa yol açan bu durumun tespiti ve ortadan kaldırılabilmesi için öncelikle serilerin durağanlıkları araştırllmalıdır (Eygü, 2018). Durağan olmayan serilerle yapılan regresyon tahminlerinde sonuçlar anlamlllı̆ını kaybetmektedirler (Eygü ve Çoşkun, 2019). Panel birim kök testleri iki türlüdür. Birincisi, yatay kesit bağımlılığ varlığına göre belirlenen 1. ve 2. ci kuşak birim kök testleri olmak üzere iki türlüdür. Yatay kesit bağımlılığının yokluğu 1. kuşak varllğı ise 2. kuşak panel birim kök testleri için tercih sebebidir. 1. kuşak panel birim kök testleri; Levin, Lin ve Chu (LLC), Harris ve Tzavalis (HT), Breitung, Hadri, Im, Pesaran ve Shin (IPS) ve Fisher Genişletilmiş Fuller (Fisher ADF) ve Fisher Philips Perron (Fisher PP) 


\section{İŞLEYEN}

Beşeri Sermaye ve Doğrudan Yabancı Yatırımlarının Ekonomik Büyüme ile İlişkisi: OECD Ülkeleri Üzerine Panel Veri Analizi

panel birim kök testleridir. 2. kuşak panel birim kök testleri; Choi Fisher Genişletilmiş Dickey Fuller, Görünürde İlişkisiz Regresyon Genişletilmiş Dickey Fuller (SURADF), Moon ve Perron, Im, Pesaran ve Shin (CIPS), Yatay Kesit Genişletilmiş KPSS ve PANICCA panel birim kök testleridir (Yerdelen Tatoğulu, 2018). Bu çalışmada, yapılan yatay kesit bağımlılık testinden sonra ikinci kuşak testinin yapılması uygun görülmüş ve kullanılan CIPS birim kök testi aşağıda detaylı şekilde ele alınmıştır.

Pesaran (2004) yatay kesit bağımlılık sorunu ile ilgili basit bir yöntem önermiştir. Phillips ve Sul (2003) yaklaşımındaki gibi artık terimler için heterojen faktör yükleri ile tek faktörlü model ele alırken farklı olarak sapmalara dayanan birim kök testi yerini bireysel serilerin gecikmeli düzeylerinin ve bir farklarının yatay kesit ortalamalarını DF ya da ADF regresyonuna faktörler olarak ilave etmiştir.

$$
\Delta Y_{i, t}=\alpha_{1}^{1}+p_{i} Y_{i, t}+c_{i} \bar{Y}_{t-1}+d i \Delta \bar{Y}_{t}+V_{i, t}
$$

yukarıdaki denklemde

$$
\bar{Y}_{t-1}=\left(\frac{1}{N}\right) \sum_{i=1}^{N} Y_{i, t-1} \text { ve } \Delta Y_{t}=\sum_{i=1}^{N} \Delta Y_{i, t}
$$

olarak tanımlanmaktadır. $p_{i}$ nin EKK tahmincisinin t istatistiği $t_{i}(\mathrm{~N}, \mathrm{~T})$ ve Pesaran "e 1 bireysel yatay kesitlere dayanan ADF testi de CADF olarak gösterilsin. Bununla birlikte testin, küçük zaman boyutu durumlarında aykırı değerlerin olmadı̆̆ı durumda CADF* olarak gösterilsin. İki durumda da ana fikir CAD

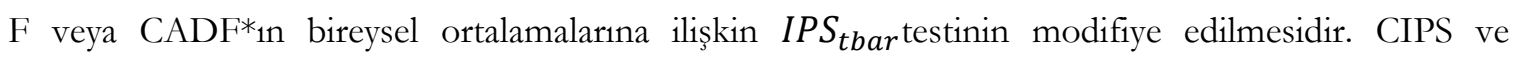
modifiye edilmiş test istatistiği;

$$
\begin{aligned}
C I P S & =\frac{1}{N \sum_{i=1}^{N} t_{i}} \\
\text { CIPS }^{*} & =\frac{1}{N \sum_{i=1}^{N} t_{i}^{*}}
\end{aligned}
$$

Panel birim kök için temel hipotezler aşağıda yer aldı̆̆1 gibidir;

$H_{0}$ : Seride birim kök vardır (Seri dură̆an değildir).

$H_{1}$ : Seride birim kök yoktur (Seri durağandir).

CIPS test istatistik değerlerinin kritik tablo değerlerinden mutlak değer olarak büyük olması halinde temel hipotez (seride birim kök vardır) ret olunur ve ilintili birim-panel geneli için alternatif hipotez (seride birim kök yoktur) kabul edilir (Pesaran, 2007, s. 265-312).

\section{Eşbütünleşme Testi}

Pedroni (1999, 2004) eşbütünleşme analizleri yapılırken heterojenliğe izin veren bazı testler önermiştir. Bu testler iki grupta incelenmektedir. Birinci gruptaki testlerde, grup zaman serilerindeki yatay kesitler içinde ayrı olarak hesaplanan eşbütünleşme testlerinin ortalaması kullanılmaktadır. İkinci grupta, istatistikler gruplanmakta ve ortalama bir parça olarak yapılmaktadır. Pedroni eşbütünleşme testinin temeli, Engle-Granger testine dayanmaktadır. Pedroni eşbütünleşme testi, durağan olmayan ancak serilerin birinci mertebeden durağan olduğu hallerde geçerlidir (Ergün ve Atay Polat, 2015, s. 126). Pedroni, yedi adet eşbütünleşme istatistiği geliştirmiştir. Bunların dört tanesi grup içi iken üç tanesi grup arasıdır (Asteriou ve Hall, 2007, s. 374).

Panel verilerde eş-bütünleşme testi, $\mathrm{H}_{0}$ eş-bütünleşme yoktur şeklindeki yokluk hipotezini analiz eder. Pedroni testinde ilk olarak, ileri sürülen eş-bütünleşme regresyonundan artıkları elde etmektedir. En genel durumda $t=1,2, \ldots, T ; i=1,2, \ldots, N$ ve $m=1,2, \ldots, M$ olmak üzere eş-bütünleşme regresyonu aşağıdaki gibi yazilir.

$$
y_{i, t}=\alpha_{i}+\delta_{i t}+\beta_{1 t} X_{1 i, t}+\beta_{2 t} X_{2 i, t}+. . .+\beta_{M t} X_{M i, t}+\varepsilon_{i}
$$

Çalışmada Westerlund (2007) Panel Eşbütünleşme Testi kullanılmıştır. Bu teste ait bilgiler aşağıda detaylı şekilde ele alınmıştır. 
Eşbütünleşme testlerinde tanımlanan Westerlund (2007) panel eşbütünleşme testinin, birimler arası korelasyonun varlığında dirençli kritik değerleri bootstrap süreci sonucunda elde edilebilmektedir. Westerlund (2007) panel verilerle çalışırken eşbütünleşmenin varllğııı sınamak için, hata düzeltme modeli temelli 4 adet panel eşbütünleşme testi önermiştir. Testlerin temelinde, her birimin kendi hata düzeltmesine sahip olup olmadığına karar verilmesi yoluyla eşbütünleşmenin varllğını sınamak vardır (Tatoğlu, 2018, s. 200-201). Westerlund (2007) panel eşbütünleşme testine ait hipotez testleri;

$H_{0}$ : Değişkenler arasında eş bütünleşme yoktur

$H_{\text {: }}$ : Değişkenler arasında eş bütünleşme vardır, şeklinde kurulmaktadır.

Grup ortalama test istatistikleri olan $G_{\alpha}$ ve $G_{\tau}$ değerlerinin hesaplanmasında her bir kesit için hata düzeltme modelinin tahmin edilmesi gerekmektedir. Grup ortalama test istatistikleri,

$$
G_{\alpha}=\frac{1}{N} \sum_{i=1}^{N} \frac{T \hat{\alpha}_{i}}{\hat{\alpha}_{i}(1)} \quad G_{\tau}=\frac{1}{N} \sum_{i=1}^{N} \frac{\hat{\alpha}_{i}}{S E\left(\hat{\alpha}_{i}\right)}
$$

olarak ve panelin bir bütün olarak analiz edilmesi için Westerlund (2007) eşbütünleşme test istatistikleri ise,

$$
P_{\alpha}=T \hat{\alpha} \quad P_{\tau}=\frac{\hat{\alpha}}{S E(\hat{\alpha})}
$$

olarak verilmiştir. $\alpha_{i}$ 'in yarı parametrik karnel tahmincisi $\hat{\alpha}_{i}$ ve $\hat{\alpha}_{i}$ 'nin standart hatası ise $S E\left(\hat{\alpha}_{i}\right)$ ile gösterilmiştir.

\section{Uygulama ve Bulgular}

Bu bölümde verilerimizin durağanlığını sınamak için kullanacağımız birim kök testi kuşaklarını belirlemek adına ilk olarak Yatay Kesit Bağımlılık testi yapılmıştır. Yapılan test sonucu ikinci kuşak birim kök testi kullanılacağ1 gözlemlenmiştir. Uygulanacak test belirlendikten sonra durağan olmayan veriler durağanlaştırllıp daha sonra eşbütünleşme testi ile değişkenler arasında eşbütünleşme olup olmadığ analiz edilmiştir. Sonuçlar aşağıda başlıklar halinde detaylı şekilde ele alınmıştır.

\section{Yatay Kesit Bağımlılık Testi}

Panel veri analizinde kullanılacak birim kök testine karar vermek için yatay kesit bağımlılık testi yapılır. Teste ait sonuçlar aşağıda yer şekildedir;

Tablo 1. Yatay Kesit Bağzmllhk Testi

\begin{tabular}{l|cc}
\hline Test & İstatistik & P-değer \\
\hline LM & 4151 & 0.000 \\
LM adj* & 210.7 & 0.000 \\
LM CD* & 59.56 & 0.000 \\
\hline
\end{tabular}

Yukarıda yer alan test sonuçlarına göre tüm $P$ değerleri kritik değer 0.05 ’ten küçüktür. Bu durumda test analizi için ikinci kuşak birim kök testinin kullanılması uygundur.

$\mathrm{H}_{0}$ : I. kuşak birim kök testi

$\mathrm{H}_{1}$ : II. kuşak birim kök testi, $\mathrm{p}<0.05 \mathrm{H}_{0}$ reddedilip $\mathrm{H}_{1}$ kabul görür ve II. kuşak birim kök testi uygundur sonucu elde edilir.

\section{Panel Birim Kök Testi}

Serilerin durağanlığını test etmek için yatay kesit bağımlılık testinde yer aldığı üzere ikinci kuşak birim kök testlerinden CIPS (Cross Sectionally Augmented IPS) testi kullanılmıştır. CIPS test istatistik değerlerinin kritik tablo değerlerinden mutlak değer olarak büyük olması halinde temel hipotez (seride birim kök vardır) ret olunur ve ilintili birim-panel geneli için alternatif hipotez (seride birim kök yoktur) kabul edilir (Pesaran, 2007, s. 265-312). Çalışmamızda düzeyde durağan olmayan verilerin birinci farkları alınarak veriler durağanlaştırılmıştır. Sonuçlar aşağıda yer aldığı gibidir; 


\section{İSLEYEN}

Beşeri Sermaye ve Doğrudan Yabancı Yatırımlarının Ekonomik Büyüme ile İlişkisi: OECD Ülkeleri Üzerine Panel Veri Analizi

Tablo 2. GSYİH İçin Birim Kök Testi

\begin{tabular}{l|ccc}
\hline & $\mathbf{0 1 0}$ & $\mathbf{0 5}$ & $\mathbf{0 0}$ \\
\hline Kritik değerler & -2.27 & -3.62 & -2.80 \\
\hline
\end{tabular}

Tablo 2 GSYİH için verilerin düzeyde durağan olmadığını göstermektedir (CIPS test istatistik değerlerinin (-1.097) kritik tablo değerlerinden mutlak değer olarak küçük olmas1). Bu durumda GSYİH için verilerin durağanlaşması adına birinci farkları alınarak veriler durağan hale getirilmiştir. Durağan GSYİH verileri Tablo 2'de yer almaktadır.

Tablo 3. GSYİH Ị̇in Birim Kök Testi

\begin{tabular}{l|ccc}
\hline & $\mathbf{0 1 0}$ & $\mathbf{0 5}$ & $\mathbf{0 0}$ \\
\hline Kritik değerler & -2.70 & -3.02 & -2.93 \\
\hline
\end{tabular}

$\mathrm{H}_{0}$ : Seri durağan değildir

$\mathrm{H}_{1}$ : Seri durağındır

GSYİH için tablo analizi yapıldığında, CIPS* tablo değerinin (-3.407) mutlak değer olarak kritik değerlerden büyük olduğu gözlenmektedir. Bu durumda $\mathrm{H}_{0}$ ret edilip seri durağındır hipotezi kabul edilir.

Tablo 4. BS İçin Birim Kök Testi

\begin{tabular}{l|ccc}
\hline & $\mathbf{0 1 0}$ & $\mathbf{0 5}$ & $\mathbf{0 0}$ \\
\hline Kritik değerler & -2.98 & -3.02 & -2.71 \\
\hline
\end{tabular}

Tablo 4., BS için verilerin düzeyde durağan olmadığını göstermektedir (CIPS test istatistik değerlerinin (-2.401) kritik tablo değerlerinden mutlak değer olarak küçük olması). Bu durumda BS için verilerin durağanlaşması adına birinci farkları alınarak veriler durağan hale getirilmiştir. Durağan BS verileri Tablo 4'te yer almaktadir.

Tablo 5. BS İ̧in Birim kÖß Testi

\begin{tabular}{l|ccc}
\hline & $\mathbf{0 1 0}$ & $\mathbf{0 5}$ & $\mathbf{0 0}$ \\
\hline Kritik değerler & -2.79 & -2.98 & -2.81 \\
\hline
\end{tabular}

$\mathrm{H}_{0}$ : Seri durağan değildir

$\mathrm{H}_{1}$ : Seri durağındır

BS için tablo analizi yapıldığında, CIPS* tablo değerinin (-3.012) mutlak değer olarak kritik değerlerden büyük olduğu gözlenmektedir. Bu durumda $\mathrm{H}_{0}$ ret edilip seri durağındır hipotezi kabul edilir.

Tablo 6. DYY Ị̇in Birim Kök Testi

\begin{tabular}{l|ccc}
\hline & $\mathbf{0 1 0}$ & $\mathbf{0 5}$ & $\mathbf{0 0}$ \\
\hline Kritik değerler & -2.98 & -2.92 & -2.81 \\
\hline
\end{tabular}

Tablo 6., DYY için verilerin düzeyde durağan olmadığını göstermektedir (CIPS test istatistik değerlerinin (-2.712) kritik tablo değerlerinden mutlak değer olarak küçük olmas1). Bu durumda BS için verilerin durağanlaşması adına birinci farkları alınarak veriler durağan hale getirilmiştir. Durağan DYY verileri Tablo 6'da yer almaktadir.

Tablo 7. DYY Ị̇in Birim Kök Testi

\begin{tabular}{l|lll}
\hline & $\mathbf{\% 1 0}$ & $\mathbf{0 5}$ & $\mathbf{\% 0}$ \\
\hline Kritik değerler & -3.08 & -3.36 & -2.91 \\
\hline
\end{tabular}

$\mathrm{H}_{0}$ : Seri durağan değildir

$\mathrm{H}_{1}$ : Seri durağındır

DYY için tablo analizi yapıldığında, CIPS* tablo değerinin (-3.412) mutlak değer olarak kritik değerlerden büyük olduğu gözlemlenmektedir. Bu durumda $\mathrm{H}_{0}$ ret seri durağındır hipotezi kabul edilir. Düzeyde durağan olmayan verilerin birinci farkı alınarak durağan hale getirildikten sonra eş bütünleşeme testi yapılmıştır. Eşbütünleşme testi aşağıda detaylı şekilde verilmiştir. 


\section{Westerlund (2007) Panel Eşbütünleşme Testi}

Westerlund (2007) testi iki veya daha fazla değişken arasında eşbütünleşme ilişkisinin test edilebilmesi için hata düzeltme modeline dayanan bir eșbütünleșme testidir. Bu test zaman serileri için geliștirilen Banerjee, Dolado ve Mestre (1998) eşbütünleşme testinin panel veri için genişletilmiş halidir. Bu testte serilerin aynı derecede durağan olmaları varsayımı yer almaktadır. Serilerimizin hepsi birinci dereceden durağan oldukları için bu varsayım sağlanmaktadır. Eşbütünleşme testimize ait çıktılar aşağıda detaylı şekilde verilmiştir.

Tablo 8. GSYIH $\rightarrow B S$ Eşbütünlessme Testi

\begin{tabular}{l|cccc}
\hline İstatisik & Değer & Z değer & P değer & Robust P değer \\
\hline $\mathrm{Gt}$ & -3.101 & -11.703 & 0.000 & 0.020 \\
\hline $\mathrm{Ga}$ & -16.091 & -9.805 & 0.000 & 0.010 \\
\hline $\mathrm{Pt}$ & -15.047 & -7.408 & 0.000 & 0.020 \\
\hline $\mathrm{Pa}$ & -10.372 & -9.001 & 0.000 & 0.000 \\
\hline
\end{tabular}

$\mathrm{H}_{0}$ : Seriler arasında eş bütünleşme yoktur

$\mathrm{H}_{1}$ : Seriler arasında eş bütünleşme vardır.

Tüm P olasılık değerlerinin kritik değer olan 0.05 'ten küçük olmalarından kaynaklı GSYİH ile BS arasında eş bütünleşme vardır. $\mathrm{H}_{0}$ hipotezi ret edilip $\mathrm{H}_{1}$ hipotezi kabul edilir.

Tablo 9. GSYIH $\rightarrow$ DYY Eşbütünleşme Testi

\begin{tabular}{|c|c|c|c|c|}
\hline İstatisik & Değer & $Z$ değer & $P$ değer & Robust P değer \\
\hline $\mathrm{Gt}$ & -3.490 & -12.309 & 0.000 & 0.010 \\
\hline $\mathrm{Ga}$ & -16.010 & -10.423 & 0.000 & 0.030 \\
\hline $\mathrm{Pt}$ & -16.309 & -9.053 & 0.000 & 0.000 \\
\hline $\mathrm{Pa}$ & -10.617 & -9.087 & 0.000 & 0.020 \\
\hline
\end{tabular}

$\mathrm{H}_{0}$ : Seriler arasında eş bütünleşme yoktur

$\mathrm{H}_{1}$ : Seriler arasında eş bütünleşme vardır.

Tüm P olasilık değerlerinin kritik değer olan 0.05 'ten küçük olmalarından kaynaklı $\mathrm{H}_{0}$ ret edilir ve GSYİH ile DYY arasında eş bütünleşme vardır hipotezi olan $\mathrm{H}_{1}$ kabul edilir.

Panel eşbütünleşme sonucuna göre değişkenler arasında uzun dönem ilişki bulunmuştur. Uzun dönem eşbütünleşme katsayılarının tahmin edilmesi ve ilişkinin yönünü belirlemek için Peseran (2015) testi uygulanmıştır sonuçlar aşağıda detaylı şekilde tablolar halinde yer almaktadır.

Tablo 10. GSYIH $\rightarrow B S$ eşbütünlesme testi

\begin{tabular}{l|lllll}
\hline GSYİH & Katsay1 & Standart Hata & $\boldsymbol{Z}$ Değeri & $\boldsymbol{P}</ \boldsymbol{Z} /$ & [\%95 Güven Aralĭg] \\
\hline BS & 1.805322 & 1.801 & 1.07 & 0.273 & -1.610 \\
\hline
\end{tabular}

Yukarıda yer alan tabloya göre BS ile GSYİH arasında uzun dönemli pozitif yönlü bir ilişkinin olduğu görülmektedir. BS'de meydana gelecek bir birimlik artış GSYIH'da 1.805'lik bir artış meydana getirmektedir.

Tablo 10. GSYIH $\rightarrow$ DYY eşbütünleşme testi

\begin{tabular}{l|llllll}
\hline GSYïH & KatsayI & Standart Hata & $\boldsymbol{Z}$ Değeri & $\boldsymbol{P}</ \boldsymbol{Z} /$ & [\%95 Güven Aralğg] \\
\hline DYY & 0.903740 & 0.719 & 1.14 & 0.301 & -1.707 & 4.807 \\
\hline
\end{tabular}

Yukarıda yer alan tabloya göre DYY ile GSYİH arasında uzun dönemli pozitif yönlü bir ilişkinin olduğu görülmektedir. DYY'de meydana gelecek bir birimlik artış GSYİH'da 0.90’lık bir artı̧ meydana getirmektedir.

\section{Tartışma, Sonuç ve Öneriler}

Çalışmamızda 36 OECD ülkesine ait Beşeri Sermaye (BS) ve Doğrudan Yabancı Yatırımlarının (DYY) Ekonomik Büyüme (GSYİH) ile ilisski panel eşbütünleşme testi ile analiz edilmiştir. Sonuçta BS ve DYY ile GSYİH arasında eşbütünleşme olduğu sonucu elde edilmiştir. Ayrıca uzun dönemli eşbütünleşme testi sonucunda da BS ve DYY ile GSYIH arasında pozitif yönlü bir ilişkinin olduğu sonucu elde edilmiştir. 


\section{İŞLEYEN}

Beşeri Sermaye ve Doğrudan Yabancı Yatırımlarının Ekonomik Büyüme ile İlişkisi: OECD Ülkeleri Üzerine Panel Veri Analizi

Beşerî sermayenin ampirik olarak ekonomik büyümeye katkısı bir çok çalışmada olduğu gibi bu çalışmamızda da gösterilmiştir. Ancak asıl önemli olan beşerî sermayenin nasıl arttırılacağıdır. Beşerî sermayenin birikimi en başta eğitimi gerektirmektedir. Beşerî sermayeyi sadece nicel olarak değil nitel olarak ta arttırmaya ihtiyaç vardır. Ülkeler arası gelir farklarının kapanabilmesi için beşerî sermayeyi geliştiren unsurların da geliştirilmesi gerekmektedir. Bunun için yalnızca eğitimin daha geniş kesimlere ulaştırılması değil aynı zamanda başta sanayi ve hizmet sektörleri olmak üzere tüm sektörlerin ihtiyaç duyduğu sayıda ve kalitede bireyler yetiştirilmesini sağlayacak bir eğitim anlayışı sağlanmalıdır. İşsizlerin vasıflarını ülkelerin kendi ihtiyaç duyduğu vasıflarıyla örtüştüren, sürekli eğitim programları ile çalışanların meslek içi eğitimiyle niteliklerinin arttırılması, kadınlarında iş gücüne daha fazla dâhil edilmesi, yaşam boyu öğrenme kültürünü ülkelerde oturtarak ise bu gelişimi sürdürmeyi hedeflemelidirler.

Ülkeler çeşitli ekonomik hedefleri için yabancı sermayeyi kendi ülkelerine çekmek isterler. Fakat yabancı sermayeyi istemelerinin asıl nedeni ekonomik büyümenin sağlanmasında yabanc1 yatırımların oynadığ1 roldür. Tasarrufları yetersiz olan ülkeler bu fonları kullanarak ekonomik büyümeyi sağlamak istemektedirler. Tasarruf miktarı yetersiz olan Türkiye gibi gelişmekte olan ülkeler, ülkelerine yabanc1 yatırımları çekebilmek için çeşitli hukuki ve ekonomik düzenlemeler yapmışlardır. Bu düzenlemelerin sonuç vermesiyle ülkelere sermaye girişleri hızlanmış fakat bu düzenlemelerin yetersiz oluşu ve ekonomideki yapısal sorunlar nedeniyle yabancı yatırımlar ülkeden çıkmak istemişler. Zaten ekonomik anlamda zayıf durumda olan gelişmekte olan ülkeler sermaye kaçışıyla birlikte finansal krizler yaşamış ve bu krizlerin olumsuz etkileri yıllar boyunca sürmüştür. Yabanc1 yatırımların ülkede ekonomik kalkınmaya katk1 sağlamasının yanı sıra istihdam alan yaratarak işsizliği de düşürmektedir. Bu bağlamda dış yatırımların oluşması için öncelikle ülkenin yabancı yatırımcılara güven ortamı sağlaması ve onları teşvik edecek politikalar geliştirmelidirler.

\section{Etik Beyan}

"Beşeri Sermaye ve Doğrudan Yabanc Yatımmlarnm Ekonomike Büyüme ile İlişkisi: OECD Ülkeleri Üzerine Panel Veri Analiz̨" başlıklı çalışmanın yazım sürecinde bilimsel, etik ve alıntı kurallarına uyulmuş; toplanan veriler üzerinde herhangi bir tahrifat yapılmamıs ve bu çalışma herhangi başka bir akademik yayın ortamına değerlendirme için gönderilmemiştir.

\section{Kaynakça}

Akay, Ö. (2018). Panel verilerde kümeleme analiẓi (Yüksek Lisans Tezi). Çukurova Üniversitesi Fen Bilimleri Enstitüsü, Adana.

Asteriou, D. ve Hall, S. (2007). Applied econometrics: A modern approach using eviews and microfit revised edition. New York: Pallgrave Macmillan.

Bulut, Ö. U. ve Aykırı, M. (2018). Sıcak para hareketleri bileşenlerinin varlığı. Kafkas Üniversitesi İktisadi İdari Bilimler Fakültesi Dergisi, 9(18), 539-560.

Choe, J. (2003). Do foreign direct investment and gross domestic investment promote economic growth. Review of Development Economics, 7(1), 44-57.

Ergün, S. ve Atay Polat, M. (2015). OECD ülkelerinde Co2 emisyonu, elektrik tüketimi ve büyüme ilişkisi. Erciyes Üniversitesi İktisadi ve İdari Bilimler Fakültesi Dergisi, 45, 126.

Eygü, H. (2018). Enflasyon, işsizlik ve diş ticaret arasındaki ilişkinin incelenmesi: Türkiye örneği (1990-2017). Kastamonu University Journal of Economics \& Administrative Sciences Faculty, 20(2), 96-112.

Eygü, H. ve Çoşkun, H., (2019). Türkiye'de Ar-Ge harcamaları ve ihracat ilişkisi (1990-2017). II. Uluslararası Sosyal Bilimler Kongresi, Tam Metin Bildiriler Kitabı. Gümüșhane. ss. 679-687.

Kar, M. ve Ağır, H. (1998). Türkiye'de beşerî sermaye ve ekonomik büyüme ilişkisi: Eşbütünleşme yaklaşımı ile nedensellik testi, 1926-1994. Selcuk. Üniversitesi İktisadi ve İdari Bilimler Fakültesi Sosyal ve Ekonomik Araștırmalar Dergisi, 6(11), 50-68.

Kiker, B. F. (1971). Investment in the Human Capital (Colombia: University of South Carolina Press): 5175. mie Strategy for the 90's (London: The John Hopkins University Press).

Nair Reichert, U. ve Diana W. (2001). Causality tests for cross-country panels: A new look at FDI and economic growth in developing countries. Oxford Bulletin of Economics and Statistics, 63(2), 153-171.

Okuyan, A. ve Erbaykal, E. (2008). Gelişmekte olan ülkelerde doğrudan yabancı yatırımlar ve ekonomik büyüme ilişkisi. Ekonomik Yaklașım, 67(19), 47-58.

Örnek, İ. (2008). Yabancı sermaye akımlarının yurtiçi tasarruf ve ekonomik büyüme üzerine etkisi: Türkiye örneği. Ankara Üniversitesi SBF Dergisi, 63(2), 199-217.

Pedroni, P. (1999). Critical values for cointegration tests in heterogeneous panels with multiple regressors. Oxford Bulletin of Economics and Statistics, 61(1), 653-670. 
Pedroni, P. (2004). Panel cointegration: Asymptotic and finite sample properties of pooled time series tests with An application to the PPP hypothesis. Econometric Theory, 20(3), 597-625.

Yerdelene Tatoğlu, F. (2013). Illeri panel veri analizi: Stata uygulaml. İstanbul:Beta.

Yerdelene Tataoğlu, F. (2018). Panel zaman serileri analizi: Stata uygulamalı (2. Baskı). İstanbul: Beta.

Pesaran, H. M. (2004). General diagnostic tests for cross section dependence in panels. Working Paper No:0435, University of Cambridge.

Pesaran, M. H. (2007). A simple panel unit root test in the presence of crosssection dependence. Journal of Applied Econometrics, 22(2), 265-312.

Westerlund, J. (2007). Testing for error correction in panel data. Oxford Bulletin of Economics and statistics, 69(6), 709748.

\section{EXTENDED ABSTRACT}

The relationship of human capital with economic growth has been one of the important discussion topics of modern growth literature. Human capital, which is defined as knowledge, skills and similar qualities in human beings contributing to income generating economic activities, increases with the investments made in the person and takes the place of the production process as a very important input. For this reason, the relationship between human capital and economic growth is one of the areas of interest in researchers who examine the sources of growth, as well as in institutions and boards that form development policies. Since the science of economics was born, the concept of human capital has been used, but opinions that the human factor is a different element of production are mostly II. After World War II, it began to be studied theoretically.

Barro and Lee (1992, 199-213) conducted an empirical study using 129 years of data from 129 countries between 1960-1985. In this study, enrollment rates in primary, secondary and high school levels of the countries were examined. In the study, it was concluded that the effect of human capital on investments and productivity on physical capital is positive, and that the effect of investments and productivity on economic growth is also positive. Therefore, it is concluded that human capital accumulation has a positive effect on economic growth.

Foreign direct investments are made by making direct investments in foreign countries, acting in partnership with an existing foreign company or establishing a new company with a joint venture. According to OECD (Organization for Economic Cooperation and Development), the threshold of direct investment is a minimum, 10\% shareholder in a foreign company. At the same time, OECD rules have flexibility. Foreign direct investment is categorized as horizontal, vertical and conglomerate. Horizontal direct investment means an investment in a foreign company with the same field of work as in the country where it is located. Vertical direct investment is different from the main activities of investors, but it still means investment related to the core business.

Nair-Reichert and Weinhold (2001) examined a 25-year period for 24 developing countries. In the study, they determined that the economic effects of foreign capital movements are heterogeneous. According to the results of the study, it has been determined that there is a causality from foreign capital investments to economic growth. Choe (2003) examined the relationship between capital movements and growth for the period of 1971-1995 for 80 countries. VAR model was used in the research. According to the results of the study, a bilateral relationship was found between growth and foreign capital movements.

In our study, the relationship between the Human Capital (BS) and Foreign Direct Investments (FDI) of 36 OECD countries and Economic Growth (GDP) was analyzed by panel cointegration test. As a result, it is obtained that there is cointegration between BS and FDI and GDP. In addition, as a result of the long-term cointegration test, there is a positive relationship between BS and FDI and GDP.

The empirical contribution of human capital to economic growth has been demonstrated in this study as in many other studies. But the main thing is how to increase human capital. The accumulation of human capital primarily requires education. There is a need to increase human capital not only quantitatively but also qualitatively. In order to close the income gap between countries, the elements that develop human capital must also be developed. To this end, an education understanding should be provided that will not only provide education to wider segments, but also raise the number and quality of individuals required by all sectors, especially industry and service sectors. They should aim to increase the qualifications of the unemployed people with the qualifications needed by the countries, to increase the qualifications of the employees with on-the-job training programs, to get more involved in the workforce 


\section{İŞLEYEN}

Beşeri Sermaye ve Doğrudan Yabancı Yatırımlarının Ekonomik Büyüme ile İlişkisi: OECD Ülkeleri Üzerine Panel Veri Analizi

in women, and to continue this development by establishing the culture of lifelong learning in the countries.

Countries want to attract foreign capital to their own countries for their various economic goals. However, the main reason why they demand foreign capital is the role played by foreign investments in ensuring economic growth. Countries with insufficient savings want to achieve economic growth by using these funds. The amount of savings is insufficient, Turkey has made several legal and economic arrangements to get foreign investment. capital inflows to Turkey by making the results of these arrangements has accelerated. However, foreign investments have started to leave the country due to the insufficiency of these regulations and structural problems in the economy. Already economically with Turkey have experienced financial crises in poor condition and capital flight, which lasted for years the negative effects of this crisis. In addition to contributing to economic development in the country, foreign investments also reduce unemployment by creating employment areas. In this context, in order for foreign investments to occur, the country should first develop policies to provide confidence and encourage foreign investors. 